This document is the accepted manuscript version of a published work that appeared in final form in the British Journal of Midwifery, copyright (C) MA Healthcare, after peer review and technical editing by the publisher. To access the final edited and published work see http://www.magonlinelibrary.com/doi/10.12968/bjom.2016.24.4.286

\title{
Clinicians in the Classroom: the Consultant Midwife
}

Abstract

This is the third in a series of articles exploring expert clinicians' participation in teaching pre-registration midwifery students in the classroom setting. This article will consider sessions facilitated by Carolyn Rooth, Consultant Midwife at Milton Keynes University Hospital NHS Foundation Trust. The role of Consultant Midwife was first introduced in the United Kingdom in 2000 (Byrom et al., 2009) with post holders attaining key senior positions within maternity services to provide professional leadership and a senior level of clinical midwifery expertise (Coster, 2006). A key element of the role of the Consultant Midwife is education, training and development (NHS Executive, 1999). Redfern et al. have suggested that whilst these advanced practitioners are practice based, they should have a key role in creating and maintaining 'partnerships between the NHS and local universities [...] to enhance education and research functions' (2003:154).

Keywords: Consultant Midwife; theory practice gap; clinical leadership; preregistration midwifery education

\section{Role and responsibilities}

Safer Childbirth: Minimum Standards for the Organisation and Delivery of Care in Labour (RCOG et al., 2007) recommended the recruitment of at least one Consultant Midwife per 900 births in order to provide adequate clinical leadership. However, despite this recommendation in an individual organisation the numbers remain small. Historically, the main focus of the Consultant Midwife tended to be either normality or public health, but more recently other areas of expertise have begun to emerge, for example high risk care. The role is diverse and highly collaborative, with Consultant Midwives linking with multidisciplinary colleagues within their own NHS Trusts and externally with peers across the United Kingdom (UK).

\section{The journey to becoming a Consultant Midwife: Carolyn's story}

I qualified as a midwife in 1989, having previously worked as a nurse in women's health. I have had clinical experience in all areas of maternity services since qualification in a variety of clinical, educational and managerial roles. Particular areas of interest include normal birth, vaginal birth after previous caesarean section, complex birth planning and anxieties and fears about childbirth. I have been a Consultant Midwife for three and a half years and 
whilst I enjoy all aspects of the role, the clinically focused and educational activities are my real passions.

\section{Why teach?}

I have always enjoyed working with students; from being a clinically based mentor to being employed within a local higher education institution for 5 years in a clinically focused role as the link between the education and placement providers. I have always valued personal learning and enjoy seeing and supporting others to learn and develop. Educationally, I have masters' level qualifications in clinical leadership, education and research which have been key in developing my role as a Consultant Midwife. Additionally my personal learning and clinical experiences have enabled me to link theory to the practice setting in facilitating teaching sessions both for student midwives and qualified staff.

\section{The sessions}

My input into the pre-registration midwifery education programme focuses on leadership in midwifery, collaborative working or areas of clinical expertise/interest - for example normality or vaginal birth after previous caesarean section. I enjoy exploring topics where I have expertise and sharing my experiences with the student midwives across the three years of the preregistration midwifery programme. Leadership and management topics feature in the teaching that I undertake with third year students. These sessions are designed to be interactive as well as informative as hearing their views, experiences and reflections encourages me to reflect on my own practice and in so doing further develop my own learning. There is also involvement in teaching sessions which focus on areas that I have an interest in developing (but wouldn't profess to be an expert), for example I have a forthcoming session on obesity.

I believe it is important for expert clinicians to be involved in pre-registration education in the classroom setting as student midwives' expectations of clinical practice, if developed solely through theoretical understanding, may be at odds with the realities practice. By discussing real-life cases in the safe environment of the classroom, students can link theory to practice thereby enhancing their problem solving and decision making skills in preparation for clinical placements (Burns and Paterson, 2005). The exploration of the realities of practice in the classroom challenges students' preconceptions and encourages them to undertake further self-directed learning to ensure they provide evidence-based care in the workplace.

The Consultant Midwife role offers a representation of a clinical career pathway offering advancement in a varied, but clinically focused role rather than one which focuses on a management or educational career. In my experience, the students view this positively and are keen to know more about the road to becoming a Consultant Midwife in addition to the individual aspects of the role itself.

\section{Student evaluation}


Feedback from students indicates that they value the input of expert clinicians into pre-registration midwifery education. It appears that the opportunity to link theory and practice in a safe environment supports and enhances meaningful learning. Whilst educational activities are a key component of the role of the Consultant Midwife, the opportunity for students to draw on the expertise and knowledge of a senior clinician through discussion acts as a catalyst for further exploration, learning and reflection. I also engage with joint teaching with Academics which I feel further enhances the links between education and placement providers; a collaborative approach the students appear to have enjoyed.

\section{Summary}

The Consultant Midwife holds a high profile and prestigious position within maternity services with the four fundamental features of the role being 'expert practice; professional leadership and consultancy; education, training and development; and practice and service development, research and evaluation' (NHS Executive, 1999:6). This challenging and multi-faceted role provides individuals with the opportunity to link theory to practice by working across education and clinical placement providers. In addition to the benefits of being taught by an expert clinician, by inviting senior clinical colleagues like Carolyn into the classroom it is also hoped that student midwives will subsequently feel more confident to interact with senior midwives in the clinical area, thereby encouraging an openly supportive, non-hierarchical working environment.

\section{References}

Burns I, Paterson I (2005) Clinical practice and placement support: supporting learning in practice. Nurse Education in Practice 5 (1) 3-9

Byrom S, Edwards G, Garrod D (2009) Consultant midwives - 10 years on! MIDIRS 19 (1) 23-25

Coster S, Redfern S, Wilson-Barnett J, Evans A, Peccei R, Guest D (2006) Impact of the role of nurse, midwife and health visitor consultant. Journal of Advanced Nursing 55 352-363

NHS Executive. (1999) Health Service Circular (HSC) 1999/217 Nurse, Midwife, and Health Visitor Consultants: Establishing Posts and Making Appointments. London: DH.

RCOG, RCM, RCOA, RCOPCH (2007) Safer Childbirth: Minimum Standards for the Organisation and Delivery of Care in Labour. London: RCOG Press

Redfern S, Guest D, Wilson-Barnett J, Pecce, R, Rosenthal P, Dewe P, Evans A (2003) Role innovations in the NHS in Leading health care organizations Dopson, S., Mark, A.L. (Editors) Basingstoke, Palgrave Macmillan. 